\title{
Effect of Health Care Quality on Nurses by Using Electronic Patients Records (EPRs) in Jordanian Private Hospital
}

\author{
Okour.KarimSaeed ${ }^{1}$, Okour.Mohammad-Noor Said Deeb ${ }^{1}$, \\ Okour.Lujain Mohammad Ali ${ }^{1}$,Melhem.Shefaa Mustafa ${ }^{1}$,ZhanchunFeng ${ }^{* 1}$ \\ ${ }^{1}$ Medicine and Health Management School, Tongji Medical College, Huazhong University of Science and \\ Technology, 13 hangkong RD, Wuhan, Hubei 430030, china.
}

\begin{abstract}
There has been limited information about the use of Electronic Patients Records (EPRs) in private hospitals of Jordan. The aim of this research is to evaluate the effect of health care quality on nurses by using electronic patient records in private Jordanian hospitals. The research will try to concentrate on the factors that may affect the health care quality for the nurses when using EPRs. All EPRs advantages and disadvantages and how it could be used in order to enhance the nurses' heath care quality will be taken in considerations to finally enhance the nursing services and make it as easy and fast as possible. Through this study knowledge is given about the use of EPRs in Jordanian private hospitals to facilitate quality health care to the patients and increase efficiency and speed at which each patient is diagnosed and medicated. From the study conducted to the medical practitioners from ages of 20 and above, indicated that $69 \%$ were moderately satisfied with the quality health care provided to the patient. 87\% of the Nurses had information about EPRs and $91 \%$ of them believe that the use of EPRs affected the quality of healthcare positively. From the same study it is clear that EPRs has been applied in many private hospitals for more than five years now.

Keywords: Health Care Quality, Electronic Patient/Health Records, Quality Improvement
\end{abstract}

\section{Overview}

\section{Introduction}

A great revolution has been achieved during the last years in Information Technology. Due to this development; IT is nowadays used in most of practical life fields. Healthcare quality is considered one of them [1]. Healthcare quality is defined as the degree of the provided health services for the population or persons that in turns improves the probability of required health outcomes; it is also related to the professional present knowledge. Reliability is considered an essential ingredient for the healthcare quality; it can be defined as the system probability to perform the required missions precisely during specific time period [2].

The health organizations are moving toward employing technology in order to improve the provided service for the patients. It is also agreed that patient information is considered in great deal of importance in order to effectively provide them with the expected level of care. The patients' information regarding to all treatments and diseases are directly stored within their records [1] [3].

\section{Health Care Quality Improvement}

Enhancing quality of healthcare is considered an essential requirement for most of health organizations. The quality improvement is recognized as the activities which are planned and performed in order to attain direct enhancement for the delivery of health care within certain settings. Now; regarding to the strategy of quality improvement then it may be recognized as all involvements which have the goal of quality gap reduction with patients. This quality gap is noticed through the routine practice [4]. The main strategies that can be followed in order to enhance the quality have been studied and concluded in [5]. These strategies can be summarized as follow [4];

$>$ Enhancing Education of the health provider by using several approaches such as conferences, handing out some educational materials and holding workshops.

$>$ Enhancing education of patients via classing or through distributing pamphlets and through family education.

$>$ Employing systems for the purposes of patients' reminder for example using self-management promoting devices.

$>$ Self-management encouraging which can be performed by for example calling patients and inform them with the needed self-management procedures.

$>$ Performing organizational changes, for example replace papered records by web-based type. 
$>$ Financial incentives which are given to the health providers depending on achieving the performance goals.

$>$ Enhancing work regulation and policy suitably with organization needs and goals.

$>$ Facilitating the clinical data relaying for the health providers.

$>$ Employing systems for the purposes of health providers' reminder for example using computer-based systems.

\section{Electronic Patient Records (EPRs)}

"Electronic Patient Records (EPRs)" can be defined as saving and transferring medical records regarding to the patients electronically. These records contain different information, such as; medical history, scans, demographic, X-rays and prescription list or any related information [6] [7]. The providers of healthcare can latterly use the stored information in order to introduce the suitable and best quality service for them. By applying HER; the hospitals are able to mange, enhance and then report the information within the quality of healthcare and safety [8].

The management of care quality and cost are considered essential requirements for the economics developing. During last few years; IT has been increasingly adopted within health organizations in order to maintain the records of patients. Some concentration is also given for the recording of data standard which in turns will result in facilitating the care consistency [9].

The data which are stored within EPRs are on great deal of importance; it also considered sensitive information that clearly affects the treatment process and the final decision about patient's case. Due to these reasons; the patient records should be in high level of Privacy and should only accessed by concerned health providers. This privacy will in turns result in developing EPRs effectively [9].

\section{Advantages for Using EHRs}

Several advantages can be achieved due to either already applying EPRs or due to replacing the papered ones with them. These advantages can be summarized as follow [8];

Care quality enhancing: due to applying EPRs; the doctors can easily and quickly transfer the patient's information to the concerned health providers. The transferring process of information is securely performed to finally ensure the best care quality for the patients. Since that all needed medical information about the patients are stored immediately within their EPRs; then the providers of health care will not supply the patients with wrong medicine which in turns may cause harm for him/her[1][10].

In addition to that; an additional version form EPRs is stored as back up so in case of disaster occurrence, the patient's information can be easily recovered. Furthermore; in case of sudden accidents the patients some times are not able to discuss their health history due to the deteriorating health situation. In these cases; the health providers could be easily recognized the needed patient's health information to quickly and effectively inform the emergency care [10].

Care efficiency enhancing: when applying EPRs; the process of lab results tracking will be facilitated due to the availability and ability of health information sharing between health providers. The lab results for example can be easily accessed by the doctors; so there will be no need to perform them again especially certain lab and X-Ray test. This will in turns minimize the side effects of radiation. Furthermore; no additional costs are needed for repeating these tests [10].

Care convenience enhancing: due to applying EPRs; the health providers will be awake and aware of altering the patients to perform several screening tests. Sharing patients' information will result in reducing the needs for filling similar forms twice. There will be also no need for any waiting for transferring patients' records between health providers since EPRs can be immediately accessed [10].

Cost reduction: the cost of healthcare is increasing day by day due to applying papered type of patient's records. These records seem to be inefficient in comparison with EPRs. In case of papered type; there is additional cost needed for filling maintaining charts and pulling in addition to the needed cost for record storage maintenance. Applying EPRs will minimize these costs as much as possible based on the following points [1];

$>$ Minimizing the process of record filling and recovering within papered records.

$>$ Reduce the needed costs for the purposes of supply and paper costs.

$>$ Decreasing the needed staff for the purposes of Chart management.

$>$ Transcription cost reduction.

\section{Privacy of EPRs}

It is agreed that the information stored within EPRs are private and it should be only accesses by authenticated and specific persons who are mainly related to patients' healthcare. So; the privacy and security for patient's information may considered as two essential issues that must be taken in considerations. Several tips points may be performed in order to ensure the privacy and security when using EPRs, which are [1][10]; 
$>$ Enabling only authorized access for this information via employing accessed control such as using PIN number or password or whatever access control means.

$>$ Applying a degree of security on the recorded information by mean of encryption in order avoid recognizing the encrypted information unless performing the decryption process using key which is only recognized by authorized persons.

$>$ Enabling the feature of Audit trail that is mainly specialist in recording all trail and attempts to access the patients' records aided with all performed changes and when it has been performed.

\section{Nursing Care}

Nursing care is considered one of the most essential care services that are provided to the patients which in turns have a great effect on the patient cure process. It is known that there are several sides who are concerned within the patient care; but nurses have great role in this care due to the continuous contact with patients during whole healing process. Generally; the nursing care is used in order to specify the patient degree of satisfaction with the provided services during whole healing process [11].

"Total Quality Management (TQM)" is considered one of the most preferable approaches that are used for the purposes of healthcare improvement. TQM includes several aspects, such as;professional knowledge, applications and competence for the technology in addition to the patients' understanding and observation for the received level of care quality. There is a strong relationship between TQM and communication quality with patients. It is also related to theinformation that is provided to the patient in addition to the behavior that the health provider follow with him/her [11].

The health providers are strongly interested with the level of care that is provided to the patients. The quality of care can be measured by the level of patient's satisfaction for the provided health care services. The nurses usually tried to provide the patients with the best possible health care which in turns will strongly affect the satisfaction of patient with overall provided health care [12].

\section{EPRs in Jordan}

Electronic health (E-health) is considered essential and critical program of the Jordanian government through which the healthcare system accountability can be ensured. The healthcare system is started to be developed by Jordanian Government through applying pilot project started in year of 2011. The project started from public Jordanian hospitals. E-health is mainly aimed to facilitate the healthcare provided to the patients via storing, retrieving and updating the patients' information electronically. This will in turns achieves better treatment process for the patients in addition to make it easier [13].

An increasing rate for adopting and employing ERPs within Jordanian hospitals occurred recently corresponding to the increasing within number of internet users. Use of ERPs will in turns results in enhancing the level of healthcare quality that is provided to the patients and making it more safe and efficient. Despite of these advantages; till now there are no guesstimates reliably concluded about ERPs adoption within Jordanian hospitals. They studied the factors that affect the adoption of ERPs within Jordanian Hospitals especially in Amman. Their survey was mainly for the private hospitals which are included within "Jordanian Ministry of Health". It can be concluded that there are several factors that limit the ERPS implementation in the concerned hospitals, such as; high cost of maintenance, capital requirements and technological factors. These barriers can be overcome via applying specific strategy that mainly concerned within the financial support, technical stuff training and interoperability. This will in turns encourage and ease the employment of ERPS in more efficient procedure [14].

According to [15]; the challenges that face the use of ERPs in Jordanian hospitals have been studied and investigated. It can be concluded that Jordan is now considered one of the developed countries. Despite this development; there are some limitations within the modern system of information management that are mainly concerned in facilitating, storing and retrieving the medical data. They investigated the most common factors that affect the use of ERPs in Jordan. They concluded that there are mainly four categories for Jordanian hospitals, which are; "Ministry of Defense", government, Private sector and universities hospitals. Generally there is a variation within the degree of ERPs implementation within these hospitals between full and partial implementation. Different types of hospitals with different degrees of ERPs implementation were considered during their study. They concluded that that a great role is assigned to the leadership of organization in supplying it with the needed resources and time in order to use ERPs. The initial costs that are needed to cover the expense of first installation. This means that some of the capital must be assigned to the system infrastructure in case that the organizations decide adopting and employing ERPS. 


\section{Main ResearchQuestion}

Based on the research aim; the main research question that will be tried to studied and investigated through this research is "what is the effect of healthcare quality on nurses by using EPRs in Jordanian private hospitals". Several sub question raise from main question, which are;

$>$ What are the factors that can improve healthcare quality provided by nurses?

$>$ What are the facilities that are provided to the nurses when using EPRs in comparison with papered records?

$>$ What are the probable risks of EPRS that may limit the adopting for them in private hospitals?

$>$ What are the factors that affect the healthcare quality when applying EPRs?

\section{Study Design, Sampling and Procedure}

\section{Methods}

The survey was conducted between (write actual dates) June 5th to June 15th 2014; it was conducted in 4 private hospitals (write actual hospitals) where four departments took part in the survey, these departments are: Children, Surgery, and gynecology and esoteric. The survey has been distributed as hardcopy papers within these departments during break hours. The selected area was chosen because the private hospitals have been using EPRs for quite a while and the nurses have good experience with them. The total number of the people interviewed were 100 in which $52 \%$ were female and $48 \%$ male, from the age of 20 years. These 100 interviewers are distributed as follow; 24 nurses from children department, 26 nurses from surgery department, 26 nurses from esoteric department and 24 nurses from Gynecology department. 87\% of the total number of people who took part in the interview had perfect knowledge of EPRs and based on the evidence of the record obtained most of the participating hospitals had used the EPRs for more than 5 years.

\section{Questionnaire}

The objective of questionnaire is to assist obtain information about the use of EPRs in private hospitals and their relevance in improving Quality healthcare, the researcher in consultation with the experts in in the medical field developed the questionnaires. Other than that, we reviewed other questionnaires relating to EPRs from other sources. The final questionnaire had three parts: part one was the participant's basic personal information like age, gender and experience, this part had only three questions. The second part was dealing with the personal views on the healthcare quality, Nurses salaries, and their views on paper recording, participants' knowledge on EPRs and the period of time EPRs has been applied in the hospital. The part had six questions. The final part measured the degree of approval of EPRs applications in the medical field and in private hospitals with five parts to select, strongly agree, agree, neutral, Disagree or strongly disagree. The participants were only allowed to kick in one of the five parts for their views; the final part had 13 questions. The questionnaire was generated and tested in both English and local language (Name the Language).

\section{Ethics Statement}

Just before the data collection activity took place, the participants who were entirely medical practitioners were briefed on the study purpose, guided through on how to fill the questionnaire and the technical terminologies were explained to them. Research assistants then distributed to the medical practitioners the questionnaires during the $1 \frac{1}{2}$ hours lunch break. Assurance of confidentiality was given to the participants and should not indicate their names in the questionnaires. The participants were also guaranteed that participation was out of free will and allowed to decline answering any question they feel not to, the consent for this exercise was obtained from the hospitals administrators and the medical superintendents. More so this study was approved by the ministry of health, Jordan.

\section{Statistical Analyses}

After the filling of all the questionnaires, the data was entered into excel and then exported to Statistic Package for Social Science (SPSS) for windows 7, 32 bits, version 21 software (IBM Inc. Armonk, New York, U.S) for analysis. Descriptive and analytical statistics was used to identify the demographic factors and other responses of the questionnaires as per the nature of question. Numbers and percentages were used to present categorical data.

\section{Socio-demographic Characteristics}

\section{Results}

For the 100 medical practitioners that took part in the exercise, the mean age range was between 25-30 years, $52 \%$ of the population was female and $100 \%$ of the respondents were medical practitioners. The highest number of the participant was from the surgery department which both male and female were interviewed, in the 
gynecology department only two male were interview while in esoteric only male were interviewed and finally the children department only female were interviewed.

Table 1:Personal Information

\begin{tabular}{|c|c|c|c|c|c|c|c|c|c|c|}
\hline & \multicolumn{2}{|c|}{ Gender } & \multicolumn{4}{|c|}{ Age (year) } & \multicolumn{4}{|c|}{ Department } \\
\hline & $\begin{array}{c}\text { Femal } \\
\text { e }\end{array}$ & Male & $20-25$ & $25-30$ & $30-35$ & $\begin{array}{c}\text { More } \\
\text { than } \\
\mathbf{3 0}\end{array}$ & $\begin{array}{c}\text { Childre } \\
\text { n }\end{array}$ & esoteric & Gynecology & Surgery \\
\hline Frequency & 52 & 48 & 15 & 49 & 20 & 16 & 24 & 26 & 24 & 26 \\
\hline Percent & 52.0 & 48.0 & 15.0 & 49.0 & 20.0 & 16.0 & 24.0 & 26.0 & 24.0 & 26.0 \\
\hline Valid Percent & 52.0 & 48.0 & 15.0 & 49.0 & 20.0 & 16.0 & 24.0 & 26.0 & 24.0 & 26.0 \\
\hline $\begin{array}{c}\text { Cumulative } \\
\text { Percent }\end{array}$ & 52.0 & 100.0 & 15.0 & 64.0 & 84.0 & 100.0 & 24.0 & 50.0 & 74.0 & 100.0 \\
\hline
\end{tabular}

\section{Knowledge and Facts about EPRS}

From the survey done, $87 \%$ of the participants had perfect knowledge about the EPRs, the participants argues that the manual records have great medical errors hence argues in favor of EPRS. A greater percent of the nurses $(69 \%)$ and moderately satisfied with the quality of service offered as a result of EPRs and $15 \%$ are strongly satisfied by the quality of service. We can argue that the nurses have perfect knowledge of the EPRs as most of them states that EPRs was applied more than five years ago. With $36 \%$ having experience in EPRS and $49 \%$ having more than 5 years' experience it is evident to state that the nurses have great knowledge of EPRs. From the study $91 \%$ believe that the EPRs affect the quality of healthcare.

Table 2: Yes and No views Questions

\begin{tabular}{|c|c|c|}
\hline Question & Yes \% & No \% \\
\hline $\begin{array}{c}\text { From your point of view as a nurse; do think that using paper medical records may cause } \\
\text { medical errors }\end{array}$ & $\mathbf{7 0}$ & $\mathbf{3 0}$ \\
\hline Do you have any information about Electronic Patient Records (EPRs) & $\mathbf{8 7}$ & $\mathbf{1 3}$ \\
\hline $\begin{array}{c}\text { From your point of view as a nurse; do you think that health care quality is affected by } \\
\text { applying EPRs }\end{array}$ & $\mathbf{9 1}$ & $\mathbf{9}$ \\
\hline
\end{tabular}

Table 3: provided healthcare satisfaction degree and Nurse's Hospital experience in applying ERPs

\begin{tabular}{|l|c|c|c|c|c|c|c|}
\hline \multirow{2}{*}{} & \multicolumn{2}{|l|}{$\begin{array}{l}\text { Are you satisfied with the health care } \\
\text { quality that you provide to the patients? }\end{array}$} & \multicolumn{2}{l|}{$\begin{array}{l}\text { Since what does ERPs is applied in your } \\
\text { hospital (years)? }\end{array}$} \\
\cline { 2 - 8 } & $\begin{array}{c}\text { Moderate } \\
\text { Dissatisfied }\end{array}$ & $\begin{array}{c}\text { Moderate } \\
\text { Satisfied }\end{array}$ & $\begin{array}{c}\text { Strongly } \\
\text { Satisfied }\end{array}$ & $1-3$ & $3-5$ & $\begin{array}{c}\text { Less } \\
\text { than } 1\end{array}$ & $\begin{array}{c}\text { More } \\
\text { than 5 }\end{array}$ \\
\cline { 2 - 8 } & 15 & 69 & 16 & 11 & 36 & 4 & 49 \\
\hline Frequency & 15.0 & 69.0 & 16.0 & 11.0 & 36.0 & 4.0 & 49.0 \\
\hline Percent & 15.0 & 69.0 & 16.0 & 11.0 & 36.0 & 4.0 & 49.0 \\
\hline Valid Percent & 15.0 & 84.0 & 100.0 & 11.0 & 47.0 & 51.0 & 100.0 \\
\hline Cumulative Percent & & & & & & \\
\hline
\end{tabular}

\section{Degree of Approval by the Nurses}

From the research a greater percent of the participants agreed with the presence of EPRs in their hospitals, for instance most of the nurses agreed that the quality can be increased by decreasing the needed time patient's records by use of EPRs. At the same time a greater \% of the nurses approved that the use of EPRs improves the quality of healthcare if the record of the client history can easily be accessed, if there is readily available data about the patient,. The needed cost of compiling the information of a single client is also decreased by the use of EPRs.

Table 4: Degree of approval by the Nurses in percentage

\begin{tabular}{|c|c|c|c|c|c|}
\hline Question & $\begin{array}{c}\text { Strongly } \\
\text { agree }\end{array}$ & Agree & Neutral & Disagree & $\begin{array}{l}\text { Strongly } \\
\text { disagree }\end{array}$ \\
\hline $\begin{array}{l}\text { health care quality can be enhanced by decreasing } \\
\text { the needed time to attain the patients records when } \\
\text { using EPRs }\end{array}$ & 48 & 36 & 5 & 5 & 6 \\
\hline $\begin{array}{l}\text { Health care quality is affected by the easiness of } \\
\text { recognizing the patient's history when using EPRs }\end{array}$ & 30 & 46 & 15 & 6 & 3 \\
\hline $\begin{array}{l}\text { Health care quality can be enhanced by the } \\
\text { availability of more data about patients' case by } \\
\text { using ERPs. }\end{array}$ & 29 & 41 & 23 & 2 & 5 \\
\hline $\begin{array}{l}\text { The health care quality is affected by the Privacy of } \\
\text { patients' information that can be guaranteed when } \\
\text { using EPRs. }\end{array}$ & 30 & 48 & 13 & 6 & 3 \\
\hline Health care quality is affected by the ability of & 24 & 46 & 21 & 6 & 3 \\
\hline
\end{tabular}




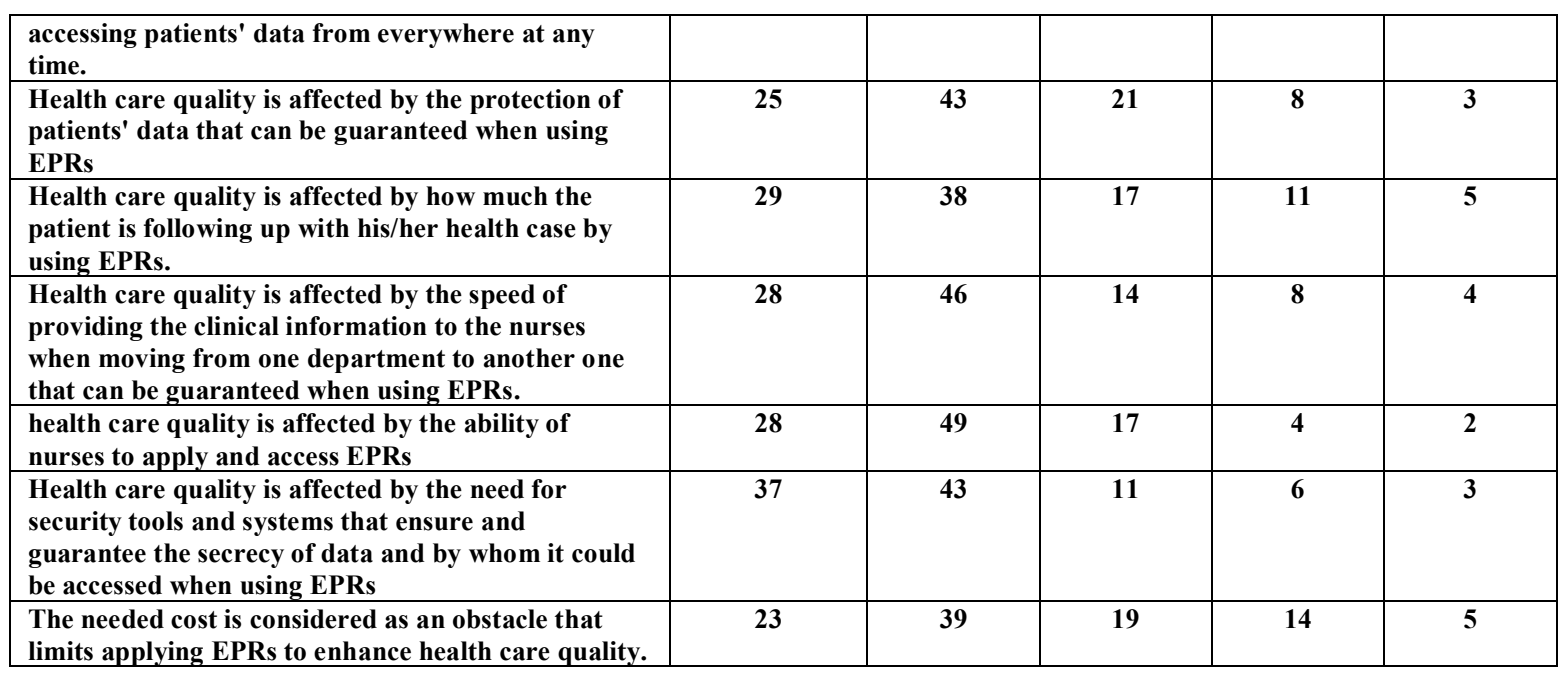

\section{Discussion}

There have been few studies about the use of EPRs use in the private hospitals of Jordan, the most prominent issues that were analyzed thoroughly by the research is the relationship between the quality health care and the use of Electronic Patient Records systems. It is evident from the research that nurses in the private hospitals of Jordan are aware of the EPRs with most of the hospitals having used the systems for more than five years. Majority of the nurses falls under the category of 1-5 years of experience though with the same experience we have mixed reactions from the nurses.

When it comes to the approval of the EPRs use and its efficiency in the private hospitals the percentage of the participants who agree combined with those who strongly agree adds up to an average of $75 \%$, this is remarkable as it indicates that $3 / 4$ of the medical practitioners have faith in the EPRs and also believe that the positive strides that have been made in improving the quality of healthcare have greatly been contributed by these systems [1] [10].

On the issues relating to the security of the Electronic Patient Records, most of the nurses who took part in the research indicated that the access to the systems should be limited as if the information goes to the wrong hands it can misused hence compromising with the patients treatment. $37 \%$ strongly agree that patient's information should be secret when $43 \%$ agrees with the statement; this makes a total of $80 \%$. According to the ethics of secrecy that is supposed to be practiced by medical practitioners, no patients information should be disclosed to the third parties without the patients consent [4] [6]. For that reason the EPRs in these hospitals have security passwords and for any nurse to use the systems must be consented by the administrator of the systems by being given a password and the limit to which they should access the information of patients. This has built confidence not only to the users but also to the patients and they feel free to share their problems as they are sure their private information is safe and won't be disclosed to other parties [8].

\section{Conclusion}

The use of electronic Patient/Health Reports in the private hospitals of Jordan have greatly brought about the improvement of quality health care, this has seen even people from other countries come to Jordan private Hospitals for medical assistance. This is an indication of the efficiency and the effectiveness brought about as a result of using EPRs in hospitals. From the research it is evident that the EPRs are readily accepted by the nurse as they reduce the paper work and also increase the level of accuracy hence should be advocated for not only in private hospitals but also in private hospitals.

\section{Acknowledgements}

My thanks are hereby extended to Professor ZhanchunFeng for his supportive and helpful supervision, as well as for assisting me in every step of the project, and for providing important information and basics, which was very important research success. Special thanks for my parents for supporting me all the time and encouraging me to go further in my education, to help people and community. Also, great thanks for my lovely wife Lujain for supporting and inspiring me all the time. Further thanks are extended to everyone who helped me develop my understanding of the various nuances of the research and for everyone who believes that the knowledge is right for everyone. 


\section{References}

[1] Overview Brochure. Electronic Health Records, Cisco Systems, Inc, 2005

[2] Spath, P. INTRODUCTION TO HEALTHCARE QUALITY MANAGEMENT, 2013.

[3] Zhang, J and Patel, V. Electronic Health Records, pp: 35-36, 2008.

[4] Hughes, R. Tools and Strategies for Quality Improvement and Patient Safety. Patient Safety and Quality: An Evidence-Based Handbook for Nurses, 3, 2009.

[5] Shojania, K,J, McDonald, K, M, Wachter, R, M, Owens and D, K. Closing the Quality Gap: A Critical Analysis of Quality Improvement Strategies. Stanford University-UCSF Evidence-based Practice Center, Stanford, CA, 2004.

[6] Wulsin, L and Dougherty, A. Health Information Technology- Electronic Health Records: A Primer. California State Library, California Research Bureau, 2008.

[7] Legislative Analyst's Office. Glossary of HIT-EHR Common Terminology. Promoting Health Information Technology in California, Feb. 2007.

[8] Carroll, Sh, Edwards, J and Rodin, D. Using Electronic Health Records to Improve Quality and Efficiency: The Experiences of Leading Hospitals, Commonwealth Fund pub. 17, July 2012.

[9] Smith, S. Electronic Patient Records. Springer-Verlag London, pp: 27-57, 2013

[10] Department of Health \& Human Services USA. PRIVACY, SECURITY, ANDELECTRONIC HEALTH RECORDS. 2013.

[11] Dzomeku, V, M, Atinga B,E, T, P, and Mantey, R, E. IN-PATIENT SATISFACTION WITH NURSING CARE: A CASE STUDY AT KWAME NKRUMAH UNIVERSITY OF SCIENCE AND TECHNOLOGY HOSPITAL.International Journal of Research In Medical and Health Sciences, 2(1), pp: 19-24, May 2013

[12] Maqsood, A, S. Differences between patients' expectations and satisfaction with nursing care in a private hospital in Jordan International Journal of Nursing Practice, 18, pp: 140-146, 2012.

[13] U.S. COMMERCIAL SERVICE. Doing Business in Jordan:2013 Country Commercial Guide for U.S. Companies, 2014

[14] Al-Abdullah, M. Critical Factors Affecting Electronic Health Records Adoption in Private Hospitals in Amman, 2012.

[15] AL-nassar, B, Abdullah, M and Osman, W. Overcoming challenges to use Electronic Medical Records System (EMRs) in Jordan Hospitals. IJCSNS International Journal of Computer Science and Network Security, 11 (8), August 2011. 